\title{
Desenvolvimento de cartilha educativa para promoção do autocuidado em indivíduos com Diabetes mellitus na área rural
}

\author{
Development of educational booklet to the production of the self-care on individual with Diabetes
}

mellitus in the rural area

Desarrollo de cartilla educativa para promoción del autocuidado en individuos con Diabetes mellitus en el área rural

Mariluci Neiss

ORCID: https://orcid.org/0000-0003-1019-6214 Universidade do Estado de Santa Catarina, Brasil E-mail: marilucineiss@hotmail.com

Alexia Tailine Etges

ORCID: https://orcid.org/0000-0002-1783-5763 Universidade do Estado de Santa Catarina, Brasil E-mail: alexiatail.etges@gmail.com

Lucimare Ferraz

ORCID: https://orcid.org/0000-0002-2487-8614 Universidade do Estado de Santa Catarina, Brasil E-mail: ferraz.lucimare@gmail.com

Leila Zanatta

ORCID: https://orcid.org/0000-0003-0935-4190 Universidade do Estado de Santa Catarina, Brasil E-mail: leila.zanatta@gmail.com

\begin{abstract}
Resumo
O objetivo é descrever a construção e validação de uma cartilha educativa intitulada: "Diabetes na área rural: conhecendo a doença para prevenir complicações". Trata-se de um estudo metodológico desenvolvido no oeste de Santa Catarina, produto do mestrado profissional em Enfermagem na Atenção Primária à Saúde. O conteúdo da cartilha foi embasado nas Diretrizes da Sociedade Brasileira de Diabetes e nas fragilidades no autocuidado detectadas nos indivíduos com diabetes moradores da área da rural através da aplicação de um questionário. A validação da cartilha envolveu juízes com experiência em atendimento à população rural por meio de um questionário via Google Forms, contendo um conjunto de itens com relação ao conteúdo, validados pelo Índice de Validade do Conteúdo, considerando valores acima de $80 \%$ como válidos. A versão final impressa da cartilha possui 56 páginas, frente e verso, e tamanho de 260x185mm, contendo: capa, contracapa, sumário, apresentação e cinco capítulos. Ao todo, 11 juízes participaram de validação desta tecnologia que atingiu Índice de Validade de Conteúdo de 90\%. Conclui-se que esse material é relevante e se apresenta como provedor de conhecimento e incentivador do autocuidado através do empoderamento dessa população.
\end{abstract}

Palavras-chave: Diabetes mellitus; População rural; Tecnologia educacional; Enfermeiros; Atenção primária à saúde.

\begin{abstract}
The objective is to describe the building and validation of an educational booklet entitled: "Diabetes in a rural area: knowing the disease to prevent complications". This is a methodological study developed at Santa Catarina west, product of the professional master's in Nursing on Primary Health Care. The booklet content was based on Brazilian Society of Diabetes Guidelines and on the weakness on the self-care in the individual with diabetes living in a rural area through the application of a questionnaire. The booklet validation process involved judges with experience in the assistance to rural population by means of a questionnaire via Google Forms, containing a set of items related to content, validated by Content validity Index, considering the values above $80 \%$ as valid. The final version printed of the booklet has 56 pages, front and back, and size 260x185mm, containing: cover, back cover, summary, presentation and five chapters. Altogether, 11 judges participated of this technology validation, which reached Validity of Content Index of $90 \%$. It is concluded that this material is relevant and it is presented as knowledge provider and encourager of the selfcare through the empowerment of this population.
\end{abstract}

Keywords: Diabetes mellitus; Rural population; Educational technology; Nurses; Primary health care. 


\begin{abstract}
Resumen
El objetivo es describir la construcción y validad de una cartilla educativa titulada: "Diabetes en el área rural: conociendo la enfermedad para prevenir complicaciones" Es un estudio metodológico desarrollado em el oeste de Santa Catarina, producto de la maestría profesional em Enfermería em la Atención Primaria de Salud. El contenido de la cartilla fue basado em las Directrices de la Sociedad Brasileña de Diabetes y em las fragilidades em el autocuidado detectadas em los individuos con diabetes que viven em el área rural mediante la aplicación de un cuestionario. La validación de cartilla involucró a jueces con experiencia en atender a la población rural a través de un cuestionario vía Google Forms, que contiene un conjunto de ítems relacionados con el contenido, validado por el Índice de Validez de Contenido, considerando como válidos valores superiores al 80\%. La versión final impresa de la cartilla posee 56 páginas, en dos lados y tamaño de 260x185mm, conteniendo: Carátula inicial, carátula final, índice, presentación y cinco capítulos. En total, 11 jueces participaron de la validad de esta tecnología, que alcanzó Índice de calidad del contenido de $90 \%$. Se concluye que ese material es destacado y se presenta como fuente de conocimiento y estímulo del autocuidado a través de la capacitación de la población.
\end{abstract}

Palabras clave: Diabetes mellitus; Población rural; Tecnología educacional; Enfermeros; Atención primaria de salud.

\title{
1. Introdução
}

O Diabetes mellitus (DM) é um problema de saúde com grande relevância e em constante crescimento em todos os países (Sociedade Brasileira de Diabetes [SBD], 2019). A International Diabetes Federation (IDF, 2019) afirma que em 2019 existiam cerca de 463 milhões de portadores de DM e se as tendências atuais persistirem, o número de pessoas com diabetes foi projetado para ser superior a 578 milhões em 2030 e 700 milhões até 2045. Destes, dois terços vivem em áreas urbanas, e três em cada quatro têm idade para trabalhar.

O autocuidado é essencial no tratamento do DM. Trata-se de uma extensão do comportamento do indivíduo, que se expressa pela adesão ao tratamento medicamentoso, dietoterapia e pela prática regular de atividade física. Para que seja plena a execução do autocuidado, o paciente deve receber apoio familiar e dos profissionais de saúde, que devem orientá-los e educalos quanto à patologia e importância do tratamento (Oliveira, Almeida, Girão \& Freitas, 2016).

A Saúde Pública e a Saúde Coletiva ainda estão pouco voltadas à área rural. Essa população por estar longe dos centros urbanos, acaba apresentando dificuldades funcionais e geográficas para ter acesso aos serviços de saúde, visto que, a grande maioria dela não conta com uma equipe de saúde próxima para atendimento, restando como opção, o deslocamento para o meio urbano (Gerhardt \& Lopes, 2015).

O enfermeiro é um profissional de saúde que pode e deve fazer parte das intervenções educativas, fazendo a ponte entre conteúdos e avaliando os produtos gerados para educação em saúde. O cuidado na enfermagem pode envolver ferramentas desenvolvidas de maneira especializada para auxiliar profissionais determinados a promover um melhor cuidado à saúde das pessoas, para isso, podem contar com o auxílio das tecnologias, pois permitem a construção do saber (Salvador, Oliveira, Costa, Santos \& Tourinho, 2012).

As tecnologias da área da saúde podem ser classificadas em duras, que envolvem materiais palpáveis como os equipamentos; leve-duras que englobam os saberes; e leves que incluem a comunicação, a relação com o outro (Merhy, 2002). Nietsche (2000), propõe outra maneira para classificar as tecnologias, nomeando-as de Tecnologias Específicas da Enfermagem, sendo elas: tecnologias do cuidado, tecnologias de concepção, tecnologias interpretativas de situações de clientes, tecnologias de administração, tecnologias educacionais, tecnologias de processos de comunicação e tecnologias de modos de conduta.

Dentre essas, destaca-se a Tecnologia Educacional (TE) que é um “conjunto sistemático de conhecimentos, que torna possível o planejamento, execução, controle e acompanhamento envolvendo todo o processo educacional formal ou informal" (Moreira, Pinheiro, Florêncio \& Cestari, 2018). A TE surge de encontros e entrelaçamentos, dentro de um olhar crítico, reflexivo, criador, transformador e multidimensional entre os envolvidos e o espaço em que estão inseridos (Teixeira, 2017 como citado em Salbego, Nietsche, Teixeira, Back \& Cassenote, 2020). 
Dentre as TE, a cartilha é um material educativo que objetiva fornecer informações auxiliando pacientes, familiares, cuidadores, comunidade a tomar decisões mais assertivas sobre sua saúde (Reberte, 2008). Na literatura evidencia-se uma análise positiva das cartilhas como TE para pacientes diabéticos. Segundo o estudo realizado em 2019, as cartilhas como meio de orientação na prática do autocuidado em pacientes com DM mostraram-se satisfatórias e adequadas, uma vez que é um instrumento de baixo custo e que favorece a autonomia dos pacientes em seu tratamento e um aprofundamento sobre a temática (Torres \& Paula, 2019).

Ao buscar subsídios para a construção da cartilha educativa, os autores deste estudo realizaram uma busca na literatura para verificar a existência de cartilhas educativas disponíveis para indivíduos com diabetes moradores da área rural. Logo, verificou-se a ausência desse tipo de material. Com base nessa premissa, associada à importância do autocuidado para o sucesso do tratamento do DM e à dificuldade de acesso dos moradores da área rural aos serviços de saúde, a proposta deste estudo foi desenvolver uma cartilha educativa embasada nas principais fragilidades encontradas no autocuidado de indivíduos portadores de DM que residem na área rural. Considerando a importância desses aspectos, objetivou-se, neste estudo, descrever o processo de construção e validação da cartilha intitulada: "Diabetes na área rural: conhecendo a doença para prevenir complicações".

\section{Metodologia}

Trata-se de um estudo metodológico, que segundo Polit \& Beck (2011), envolve uma investigação dos métodos, pautada no desenvolvimento de ferramentas para análise de alcance e de impacto dos resultados. Esse tipo de metodologia de pesquisa é frequentemente usado para o desenvolvimento de tecnologias cuidativo-educacionais (TCE) podendo ser utilizada dentro do sistema de ensino, na comunidade, nas famílias, com o indivíduo e como forma de educação permanente, dentro das classes profissionais (TEIXEIRA, 2020). Este estudo foi realizado em quatro etapas, adaptadas de Benevides et al. (2016), sendo que aqui serão descritas a terceira e a quarta etapa dessa modalidade de pesquisa, que representam a construção e a validação de conteúdo de uma cartilha educacional voltada ao autocuidado de usuários com DM moradores da área rural. A pesquisa foi realizada no período de novembro de 2019 a maio de 2020, em um município do oeste de Santa Catarina.

Primeiramente, foi realizada uma pesquisa de campo com o intuito de identificar as fragilidades no autocuidado dos indivíduos com DM moradores da área da rural. Nessa etapa participaram 11 pacientes, que atenderam aos critérios de inclusão da pesquisa: moradores de uma comunidade rural, maiores de 18 anos, com DM e atendidos por uma Estratégia de Saúde da Família (ESF) que se desloca até a comunidade para atendimento. O perfil dos participantes teve como predomínio idosos, do sexo feminino, brancos, casados e com baixa escolaridade (ensino fundamental incompleto).

Como resultado da pesquisa de campo emergiram fragilidades como: déficit de conhecimento sobre a doença, descarte incorreto de resíduos perfurocortantes e baixa adesão ao tratamento não medicamentoso, com destaque para não adesão à dieta alimentar, com alto consumo de carboidratos.

Definidas as fragilidades, foi realizado uma análise do referencial teórico sobre o tema DM, população rural e autocuidado e foi iniciada a construção da cartilha. O conteúdo para compor a cartilha foi embasado nas Diretrizes da Sociedade Brasileira de Diabetes, na sua última versão 2019-2020. Com o intuito de tornar o material mais próximo da realidade e da necessidade do público-alvo, foram utilizadas palavras de fácil compreensão, como por exemplo, o uso da palavra "açúcar" ao invés de "glicose", letras de forma maior e, explorado bastante o uso de imagens.

Para elaborar uma cartilha, alguns princípios devem ser considerados, sendo eles: linguagem clara e objetiva; visual leve e atraente; adequação ao público-alvo; fidedignidade das informações. Além desses princípios, devem ser seguidas as etapas de elaboração, sendo elas: 1) Definição do tema; 2) Definição dos tópicos que irão compor a cartilha; 3) Pesquisa bibliográfica;

4) Elaboração do roteiro; 5) Desenvolvimento da cartilha; 6) Impressão do piloto onde é recomendada a validação do material; e, 7) Impressão e distribuição (Almeida, 2017). 
Contratou-se um ilustrador e um designer gráfico, para confecção das ilustrações, formatação, configuração e diagramação das páginas da cartilha. As imagens foram coletadas na internet, em banco de imagem pago e de acesso livre, para o desenvolvimento de painéis semânticos. Após a análise dos painéis, se entendeu qual seria o melhor estilo/traço a ser usado nas ilustrações, tamanho mínimo dos caracteres e imagens, além das cores que poderiam ter uma melhor afinidade com o públicoalvo determinado. Utilizou-se o programa Adobe Illustrator 2017 (versão 21.1.0) para composição das ilustrações. As imagens para as receitas foram fotografadas com uma câmera Canon 5D MARKIII, posteriormente editadas para ajustes de cor, saturação, brilho e contraste no Photoshop 2017 (versão 21.1.1). A diagramação das páginas e montagem para editoração, foi desenvolvida no InDesing 2017 (versão 12.0.0.81). O tamanho na versão final impressa da cartilha é de 260x185mm, e, também será disponibilizada uma versão digital do mesmo material.

A cartilha possui 56 páginas, frente e verso, contendo: capa, contracapa, sumário e apresentação. A partir da página seis, o conteúdo foi divido em cinco capítulos, sendo eles: 1) O que é Diabetes? 2) Diabetes e Exercício Físico; 3) Dicas de Alimentação; 4) Mitos e Verdades; e, 5) Se eu precisar aplicar insulina, como eu aplico?

O instrumento de validação da cartilha foi baseado no estudo de Oliveira; Lopes \& Fernandes (2014) que utiliza o conceito de validade de conteúdo e aparência aplicando instrumento que busca medir a adequação dos itens avaliados com relação ao conteúdo, além da concordância entre os juízes (Polit \& Beck, 2011). Os juízes procederam à análise correspondente à concordância e à adequação de cada item (totalmente adequado, adequado, parcialmente adequado, inadequado) em seis questões de múltipla escolha, seguindo a Escala de Likert. O instrumento constava de questões abertas para comentários e sugestões. Além destas, o instrumento contou com outras seis questões, sendo quatro para o perfil do avaliador (sexo, profissão, maior titulação, anos de experiência) e duas questões voltadas especialmente ao idoso portador de DM e morador da área rural, referente à fonte/cores e palavras utilizadas.

Seguindo a orientação proposta por Teixeira e Mota, um grupo de juízes-especialistas deve ser composto entre 9 a 15 integrantes (Teixeira \& Mota, 2011). A busca por juízes ocorreu por conveniência, via indicação de profissionais com experiência em atendimento à população rural. Ao todo, foram convidados 10 profissionais de nível superior que trabalham com indivíduos com DM, moradores da área rural e atendidos na Atenção Primária à Saúde (APS) dos municípios de Xanxerê/SC, Chapecó/SC e Alpestre/RS, para participarem da validação de conteúdo. Além destes, também foram convidados uma nutricionista, para contribuir acerca do conteúdo sobre alimentação, e um profissional da área de Comunicação Social jornalismo (para consultoria acerca da aparência), totalizando assim, 12 juízes convidados. Por medidas de segurança, optou-se em não realizar a validação com o público-alvo devido à pandemia da COVID-19, pois tratam-se de idosos com doença crônica, ou seja, grupo de risco.

A validação é considerada uma estratégia que visa elaborar uma nova intervenção ou melhorar de forma significativa uma intervenção já existente (Teixeira \& Mota, 2011). Para a validação de conteúdo foi realizado um contato prévio com os juízes explicando sobre o estudo. O formulário eletrônico foi criado via Google Forms, no mês de maio de 2020, e continha o Termo de Consentimento Livre e Esclarecido (TCLE) e o instrumento de coleta de dados. A cartilha educativa, em formato PDF, e o link para acesso ao formulário de validação foram enviados para o e-mail dos profissionais.

A análise dos dados ocorreu mediante a utilização de planilhas no programa Microsoft Excel®, a partir do Índice de Validação de Conteúdo (IVC), que é obtido pelo número de respostas 1 e 2 dividido pelo número total de respostas. O IVC para atingir uma excelência de validade de conteúdo pode variar de 70 a 100\% (Polit \& Beck, 2011). Destaca-se que a proporção mínima de concordância para que o item fosse considerado válido, neste estudo, foi de $80 \%$.

O estudo atendeu a Resolução 466/12 e foi aprovado pelo Comitê de Ética em Pesquisa da Universidade do Estado de Santa Catarina com o número de parecer 3.675.167 em 31 de outubro de 2019. 


\section{Resultados e Discussão}

A partir das fragilidades no autocuidado identificadas nos usuários com diabetes e com base na literatura, iniciou-se a construção da cartilha que na sua primeira versão tinha 8 páginas. Ela continha capa, conteúdos de conceito da doença, sinais e sintomas de alteração de glicemia, instruções sobre a aplicação de insulina e descarte do material contaminado.

Após leitura e análise pela equipe, a segunda versão do material educativo expandiu até a $20^{\text {a }}$ página. Nesta etapa, foi convidada uma nutricionista para auxiliar, visto que uma das fragilidades identificadas na população-alvo foi a baixa adesão ao tratamento dietético. Portanto, nessa versão, foram acrescidas dicas de alimentação, de como montar um prato saudável, sugestão de receitas e de cardápio, além de mitos e verdades relacionados à doença e alimentação.

Para a terceira versão do material, que foi a versão enviada aos juízes, a equipe se reuniu, juntamente com o ilustrador e o designer gráfico, para revisão dos termos, cores, textos, imagens e conteúdos contidos em cada página. Foi acrescentado ao material: contracapa, sumário, apresentação da cartilha, o desenvolvimento das receitas sugeridas, para que pudessem ser realizadas as imagens reais das mesmas, e as referências utilizadas, totalizando, assim, 52 páginas.

A validação foi realizada por um grupo de 10 juízes, composto por seis (60\%) enfermeiros, 3 (30\%) médicos, e 1 (10\%) profissional de comunicação social - jornalismo, sendo este último como consultor da parte estética do material educativo. Dos 12 juízes convidados, a nutricionista e um profissional da APS não retornaram o questionário, totalizando assim, 10 juízes que validaram o material. O perfil de titulação destes profissionais indicou que três (30\%) possuíam graduação, quatro (40\%) especialização e três (30\%) mestrado. Quanto à experiência profissional, três (30\%) possuem 1 a 5 anos de experiência, quatro (40\%) de 6 a 10 anos, dois (20\%) de 11 a 15 anos e um (10\%) com mais de 20 anos. A média de experiência profissional foi de 8,2 anos. Ainda, todos apresentam experiência em atendimento à população rural.

A cartilha foi validada em sua primeira avaliação, obtendo IVC geral de 0,9 ou $90 \%$. Após avaliação dos juízes e o recebimento de suas sugestões, as mesmas foram incorporadas na cartilha. Como a cartilha já havia atingido IVC suficiente para ser considerada validada, não foi necessário ressubmeter o material à validação. O IVC individual e as perguntas utilizadas na validação de cada item estão detalhados na Tabela 1.

Tabela 1 - Avaliação do IVC individual, por item. Chapecó/SC, 2020.

\begin{tabular}{|c|c|}
\hline Itens de avaliação & IVC \\
\hline $\begin{array}{l}\text { 1. Como você considera o conteúdo apresentado para incentivar o autocuidado nos diabéticos moradores da área } \\
\text { rural? }\end{array}$ & 0,8 \\
\hline 2. Você considera os textos claros e compreensivos? & 0,9 \\
\hline 3. As ilustrações utilizadas são apropriadas para o público-alvo (diabético idoso morador da área rural)? & 0,8 \\
\hline 4. Você considera que as ilustrações apresentadas são necessárias para compreensão do conteúdo? & 0,9 \\
\hline $\begin{array}{l}\text { 5. As ilustrações e os textos motivam o idoso portador de diabetes morador da área rural para compreensão do } \\
\text { tema proposto? }\end{array}$ & 0,9 \\
\hline $\begin{array}{l}\text { 6. Como você considera a aplicabilidade da cartilha educativa no cotidiano da prática clínica da equipe de saúde } \\
\text { para auxiliar nas orientações para o autocuidado? }\end{array}$ & 0,9 \\
\hline
\end{tabular}

Fonte: Autores (2020).

O Quadro 1 apresenta a síntese das recomendações dos juízes. Foram poucos apontamentos e algumas das sugestões já estavam presentes, sendo descrito a localização no material educativo. Todas as recomendações foram aceitas e incorporadas. Realizadas essas mudanças, a cartilha expandiu para 56 páginas, chegando assim, em sua versão final, representada na Figura 1. 
Quadro 1 - Síntese da análise qualitativa das alterações sugeridas pelos juízes. Chapecó/SC, 2020.

\begin{tabular}{|ll|}
\hline Sugestão dos juízes & Localização das alterações \\
\hline Incluir a diferença entre atividade física e exercício físico & Realizado, pág. 14, 15, 16 e 17 \\
Incluir sobre a utilização das medicações além da insulina & Já estava presente na pág. 13 \\
Incluir sobre os cuidados com o pés & Já estava presente na pág. 13 \\
Incluir sobre frequência da consulta & Realizado, pág. 13 \\
$\begin{array}{l}\text { Priorizar a informação com uma fonte maior e mais contrastante, reduzir o uso de } \\
\text { cores }\end{array}$ & Realizado em todo o texto \\
Excesso de ícones que não são de domínio público & Acrescentado explicação dos ícones na \\
Rever a fonte, tamanho e cor, e quantidade de ilustrações & contracapa \\
\hline
\end{tabular}

Fonte: Autores (2020).

Abaixo, na Figura 1 está uma representação de algumas das páginas da versão final da cartilha, a qual encontra-se disponível no link https://www.udesc.br/arquivos/ceo/id_cpmenu/1311/00008931_16317276756146_1311.pdf. Já o Quadro 2 aborda os conteúdos presentes no corpo da cartilha.

Figura 1 - Representação de algumas páginas da versão final da cartilha. Chapecó/SC, 2020.
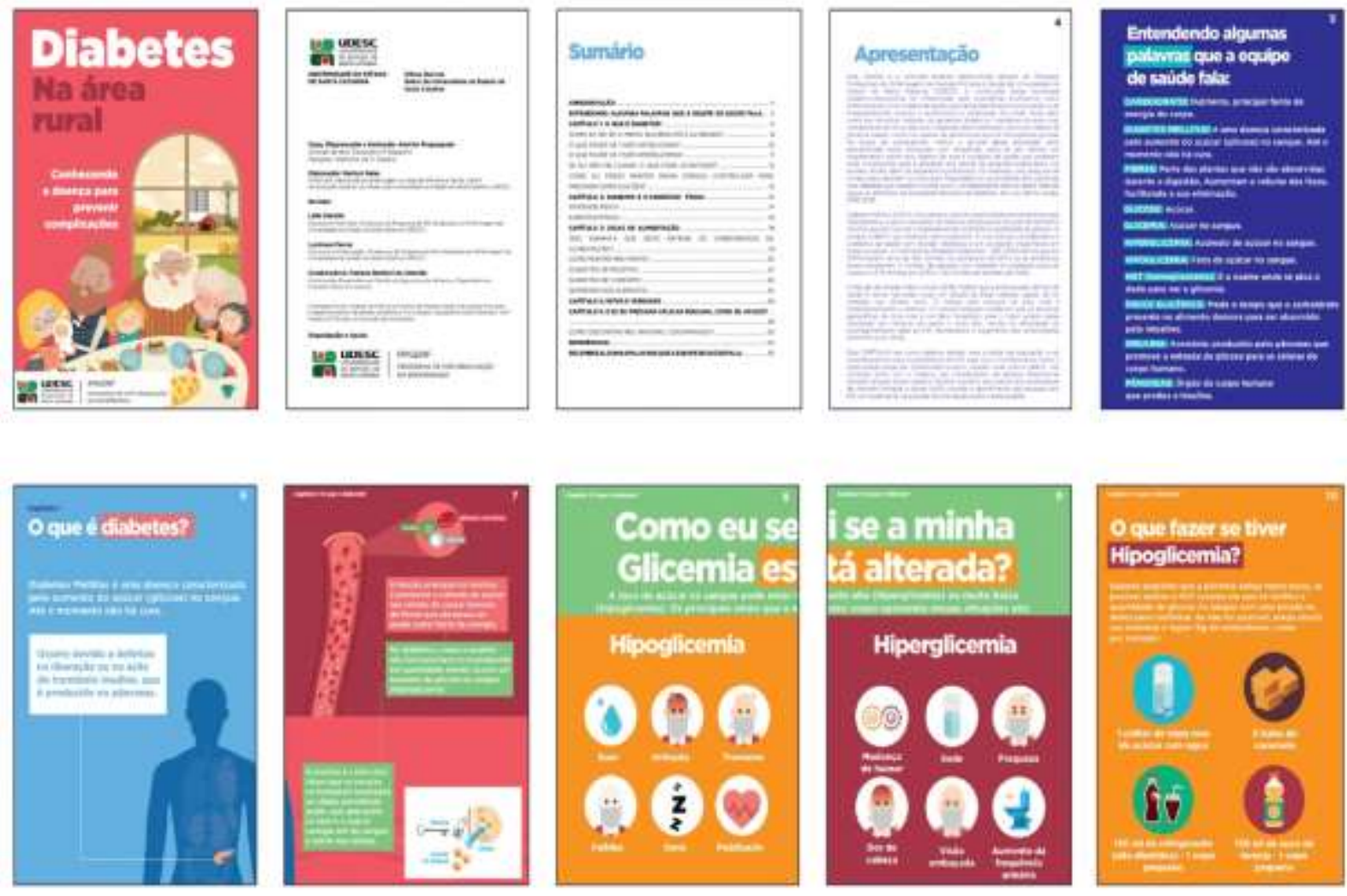

Fonte: Autores (2020). 
Quadro 2 - Apresentação dos conteúdos presentes no corpo da cartilha. Chapecó/SC, 2020.

\begin{tabular}{|c|c|c|}
\hline Capítulo & Conteúdo & Páginas \\
\hline $\begin{array}{l}\text { Entendendo algumas palavras que a } \\
\text { equipe de saúde fala }\end{array}$ & $\begin{array}{l}\text { Glossário, aborda termos técnicos descritos de maneira } \\
\text { simples para fácil compreensão. }\end{array}$ & 5 \\
\hline 1) O que é Diabetes? & $\begin{array}{l}\text { Traz o conceito da doença; representação do corpo humano } \\
\text { com localização do pâncreas e ilustração representando a } \\
\text { função da insulina; os principais sinais/sintomas da } \\
\text { hipoglicemia/hiperglicemia e quais atitudes tomar frente a } \\
\text { cada situação; principais complicações da doença e como } \\
\text { preveni-las; como manter a doença controlada. }\end{array}$ & 6 a 13 \\
\hline 2) Diabetes e exercício físico & $\begin{array}{l}\text { Aborda diferenças entre atividade física e exercício físico, } \\
\text { utilizando imagens para representar as atividades físicas } \\
\text { comumente realizadas pela população rural. }\end{array}$ & 14 a 17 \\
\hline 3) Dicas de alimentação & $\begin{array}{l}\text { Traz dicas de como montar um prato para uma refeição; } \\
\text { mostra a pirâmide alimentar; como distribuir as refeições ao } \\
\text { longo do dia; quais alimentos evitar ou dar preferência; } \\
\text { sugestões de receitas clássicas da alimentação rural como } \\
\text { pão e chimia; sugestão de um cardápio alimentar e suas } \\
\text { substituições. }\end{array}$ & 18 a 45 \\
\hline 4) Mitos e verdades & $\begin{array}{l}\text { De forma simples, esclarece algumas mitos envolvidos } \\
\text { acerca da alimentação. }\end{array}$ & 46 a 47 \\
\hline $\begin{array}{l}\text { 5) E se eu precisar aplicar insulina, } \\
\text { como eu me aplico? }\end{array}$ & $\begin{array}{l}\text { Traz, de forma ilustrada, o passo a passo para aplicação de } \\
\text { insulina, com os locais e aborda o descarte correto dos } \\
\text { insumos gerados. }\end{array}$ & 48 a 53 \\
\hline Hora de se divertir & $\begin{array}{l}\text { Jogo caça-palavras, com os termos técnicos apresentados no } \\
\text { glossário para auxiliar a fixação da nomenclatura. }\end{array}$ & 56 \\
\hline
\end{tabular}

Fonte: Autores (2020).

O aumento de casos de DM no Brasil e no mundo exige cuidados contínuos por se tratar de uma doença crônica. Nesse sentido, a educação em saúde se torna indispensável e fundamental para que indivíduos que convivem com essa doença alcancem bons resultados no tratamento. Para isso, os profissionais da área da saúde podem fazer uso de tecnologias que estimulem o pensamento crítico e auxiliem no autocuidado dos pacientes e seus familiares. Cartilhas educacionais possibilitam essa transformação social, pois são capazes de trazer clareza sobre o tema, facilitar a comunicação visual e promover acesso ao conhecimento (Moreira, 2018 como citado em Galdino, Moreira \& Cestari, 2018).

A produção de cartilhas educativas para diabéticos é avaliada positivamente. Autores que desenvolveram uma cartilha para orientação do autocuidado em diabetes, inferiram que um material escrito, desde que seja bem produzido e atenda às necessidades do grupo em questão, contribui de forma significativa para o desenvolvimento de aptidão em práticas de autocuidado e a consequente autonomia do paciente (Torres, Candido, Alexandre \& Pereira, 2009).

A escolha dos conteúdos da cartilha emergiu após pesquisa de campo que identificou fragilidades no autocuidado. Estudo realizado em 2018 sobre os saberes e práticas de cuidado adotadas pela população rural, em seu contexto cultural, com a dificuldade econômica e de acesso aos serviços de saúde, constatou a necessidade de integrar esses saberes com os do sistema convencional de saúde e investir no desenvolvimento de ações de educação popular em saúde com a população do campo (Rückert, Cunha \& Modena, 2018).

O processo cuidativo-educativo é relacional e progressista, tencionando dar valor à experiência do viver e ao contexto de vida, proporcionando aos envolvidos um pensar crítico, empoderado e com autonomia para transformar sua realidade, tornando-os atores principais de sua vida (Salbego et al., 2018)

A educação em saúde capacita o paciente a opinar e propor ações que interfiram na saúde individual, e também da família e da coletividade. Ela o emancipa, tornando-o sujeito ativo. Mas para isso é preciso orientá-lo a despertar um pensamento 
crítico, que fuja do senso comum, para que o mesmo seja capaz de refletir com embasamento, e esta transformação é desenvolvida notoriamente pelo profissional de saúde (Machado, Monteiro, Queiroz, Vieira \& Barroso, 2007)

É indispensável a orientação, não somente do paciente, mas dos profissionais de saúde quanto práticas educativas em diabetes, para que estes sejam capacitados a oferecê-las. A competência destes também abrange a interprofissionalidade, uma vez que o tratamento do diabetes mellitus envolve várias categorias profissionais, e neste âmbito o trabalho em equipe recebe destaque, no qual o enfermeiro é visto na grande maioria das vezes como líder (Santos \& Torres, 2012).

A enfermagem possui papel fundamental na orientação ao autocuidado em DM, e é o diferencial para sua plena execução pelo paciente. As intervenções realizadas pelo enfermeiro são eficazes no auxílio dos pacientes para melhorar as práticas de cuidado individual de forma eficaz (Oliveira, Almeida, Girão \& Freitas, 2016).

$\mathrm{Na}$ literatura evidencia-se a importância das ações educativas realizadas pelo profissional de saúde para paciente, família e comunidade para o controle do DM, uma vez que o conhecimento é parte essencial da realização do autocuidado. Além disso, a educação em saúde deve ser contínua e priorizar a facilidade do acesso ao conhecimento para que não seja somente uma transmissão de informação, mas sim uma ferramenta que garanta maior autonomia ao paciente. O profissional deve levar em consideração particularidades do público ao qual se dirige, assim como individualidades de cada paciente, traçando uma estratégia que cumpra com as necessidades do indivíduo (Oliveira, Almeida, Girão \& Freitas, 2016).

Nesta perspectiva é notória a alta probabilidade de eficácia da cartilha educativa voltada para pacientes que convivem com diabetes, uma vez que é um conteúdo que vai estar sempre disponível ao indivíduo e família, para ser consultado em caso de dúvidas, e norteando o autocuidado. É necessário que a mesma cumpra com as especificidades do público alvo e seja entregue após uma conversa explicativa, fazendo com que o paciente entenda, de fato, todas as informações ali contidas, voltadas a seu contexto patológico (Torres \& Paula, 2019).

A construção de materiais educativos para auxiliar indivíduos que convivem com DM é também uma necessidade, uma vez que muitos indivíduos não recebem o apoio necessário dos profissionais de saúde para o manejo da doença, o que acarreta em dificuldades para manter o controle glicêmico e também maior probabilidade de complicações (Aquino et al., 2016).

\section{Considerações Finais}

A construção da cartilha envolveu pesquisa de campo, conhecimento científico e trabalho em equipe entre os profissionais: ilustrador, designer, nutricionista, enfermeiros e farmacêutica. As contribuições dos juízes foram consideradas e incorporadas na versão final da cartilha. A cartilha foi validada segundo conteúdo e o processo incluiu profissionais da saúde da APS e uma comunicadora social da área do jornalismo, os quais receberam a nomenclatura de juízes. Salienta-se a característica não-probabilística do estudo.

A cartilha é relevante e se apresenta como um material inovador no ensino sobre autocuidado em diabetes para população rural. Poderá ser utilizada pelas equipes de saúde, pois permitirá a instrumentalização e facilitará a prática assistencial dos profissionais. Também poderá ser utilizada pelos indivíduos portadores de DM que residem na área rural, pois devido à distância geográfica até os centros urbanos, essa população não dispõe de equipe de saúde próxima para sanar suas dúvidas. Nesse sentido, a cartilha, com linguagem adequada para esse público, servirá como um instrumento provedor de conhecimento e incentivador do autocuidado através do empoderamento dessa população.

Considera-se como limitações deste estudo, o fato da cartilha não ter sido avaliada pelos usuários com diabetes atendidos na APS, portanto, sugere-se, que a cartilha seja validada por esse público também. Além disso, pretende-se avaliar o impacto que a implementação dessa tecnologia educacional gerou nesses usuários, em relação as práticas de autocuidado. 


\section{Agradecimentos}

Agradecemos à Fapesc (TO 2021TR808) pelo apoio financeiro.

\section{Referências}

Almeida, D. (2017). Elaboração de materiais educativos. Escola de Enfermagem da USP. https://edisciplinas.usp.br/pluginfile.ph p/4412041/mod_resource/content/1/ELABORA\%C3\%87\%C3\%83O\%20MATERIAL\%20EDUCATIVO.pdf.

Aquino, J., Baldoni, A., Oliveira, C., Figueiredo, R., Cardoso, C., Pereira, M., \& Sanches-Giraud, C. (2016). Educational booklet on diabetes: construction and contente validation. Semina Ciências Biológicas e da Saúde, 37 (1). https://pesquisa.bvsalud.org/portal/resource/pt/biblio-836599

Benevides, J. L., Coutinho, J. F. V., Pascoal, L. C., Joventino, E. S., Martins, M. C., Gubert, F. A., \& Alves, A. M. (2016). Development and validation of educational technology for venous ulcer care. Revista da escola de enfermagem da USP, 50(2), 306-312.

Eberte, L. (2008). Celebrando a vida: construção de uma cartilha para a promoção da saúde da gestante [Doctoral dissertation, Universidade de São Paulo]. http://www.teses.usp.br/teses/disponiveis/7/7132/tde-05052009-112542/pt-br.php

Galdino, Y., Moreira, T., \& Cestari, R. (2018). Construção e validação de cartilha educativa: trabalhando inovações tecnológicas. UECE.

Gerhardt, T., \& Lopes, M. (2015). O rural e a saúde: compartilhando teoria e método. Editora da UFRGS.

International Diabetes Federation (IDF). (2019). Diabetes Atlas. Brussels, Belgium. https://www.diabetesatlas.org/uploa d/resources/2019/IDF_Atlas_9th_Edition_2019.pdf

Machado, M., Monteiro, E., Queiroz, D., Vieira, N., \& Barroso, M. (2007). Integralidade, formação de saúde, educação em saúde e as propostas do SUS: uma revisão conceitual. Ciência e saúde coletiva, 12(2). https://www.scielo.br/scielo.php?script=sci_arttext\&pid=S1413-81232007000200009

Merhy, E. (2002). Saúde: a cartografia do trabalho vivo. Hucitec.

Nietsche, E. (2000). Tecnologia emancipatória: possibilidade ou impossibilidade para a práxis de enfermeiros? Unijuí.

Oliveira, G., Almeida, A., Girão, A., \& Freitas, C. (2016). Intervenções de enfermagem para promoção do autocuidado de pessoas com diabetes tipo 2: revisão integrativa. Revista Eletrônica de Enfermagem, 18. https://www.revistas.ufg.br/fen/article/view/38691/22111

Oliveira, S. C. de, Lopes, M. V. O., \& Fernandes, A. N. C. (2014). Construção e validação de cartilha educativa para alimentação saudável durante a gravidez. Revista Latino-Americana de Enfermagem, 22(4), 611-620.

Polit, D., \& Beck, C. (2011). Fundamentos de Pesquisa em Enfermagem. Avaliação de evidências para a prática da enfermagem. Artmed.

Reberte, L. (2008). Celebrando a vida: construção de uma cartilha para a promoção da saúde da gestante [Dissertação de Mestrado, Universidade de São Paulo].

Rückert, B., Cunha, D., \& Modena, C. (2018). Saberes e práticas de cuidado em saúde da população do campo: revisão integrativa da literatura. Interface (Botucatu).

Salbego, C., Nietsche, E., Teixeira, E., Girardon-Perlini, N., Wild, C., \& lha, S. (2018). Tecnologias cuidativo-educacionais: um conceito emergente da praxis de enfermeiros em contexto hospitalar. Revista Brasileira de Enfermagem, 71. https://www.scielo.br/pdf/reben/v71s6/pt_0034-7167-reben-71-s6-2666.pdf.

Salbego, S. C., Nietsche, E., Teixeira, E., Back, A., \& Cassenote, L. (2020). Tecnologias Cuidativo Educacionais: um conceito em Desenvolvimento. Moriá.

Salvador, P., Oliveira, R., Costa, T., Santos, E., \& Tourinho, F. (2012). Tecnologia e inovação para o cuidado em enfermagem. Revista Enfermagem UERJ, 20 (1), 111-117. https://www.e-publicacoes.uerj.br/index.php/enfermagemuerj/article/view/4004/2773

Santos, L., \& Torres, H. (2012). Práticas educativas em diabetes mellitus: compreendendo as competências dos profissionais da saúde. Texto contexto: enfermagem, 21 (3), 574-580.https://www.scielo.br/scielo.php?pid=S010407072012000300012\&script=sci_arttext\&tlng=pt

Sociedade Brasileira de Diabetes (SBD). (2019). Diretrizes da Sociedade Brasileira de Diabetes 2019-2020. Clannad. http://www.saude.ba.gov.br/wpcontent/uploads/2020/02/Diretrizes-Sociedade-Brasileira-de-Diabetes-2019-2020.pdf

Teixeira, E., \& Mota, V. (2011). Tecnologias educacionais em foco. Difusão.

Teixeira, E. (2020). Desenvolvimento de Tecnologias Cuidativo-Educacionais. Editora Moriá.

Torres, H., Candido, N., Alexandre, L., \& Pereira, F. (2009). O processo de elaboração de cartilhas para orientação do autocuidado no programa educativo em Diabetes. Revista Brasielira de enfermagem, 62 (2), 312-316. https://www.scielo.br/scielo.php?script=sci_arttext\&pid=S0034-7167200900020 $0023 \& \operatorname{lng}=\mathrm{pt} \& \mathrm{t} \operatorname{lng}=\mathrm{pt}$

Torres, H., \& Paula, D. (2019). Avaliação da cartilha para orientação da prática do autocuidado em Diabetes Mellitus. Revista Enfermagem UERJ, 27, e7722. https://doi.org/http://dx.doi.org/10.12957/reuerj.2019.7722. 